\title{
O SUBJECTIVISMO DA FENOMENOLOGIA HUSSERLIANA E A EXIGÊNCIA DE UMA FENOMENOLOGIA
} ASSUBJECTIVA $^{1}$

Jan Patočka

A fenomenologia husserliana aspira a uma Filosofia Primeira, a qual deve operar uma fundamentação absoluta do conhecimento, a partir de bases estritamente científicas, numa evidência re-executável por cada um. A fenomenologia deve, com isso, ser ela própria uma ciência, a ciência apriorística das legalidades de essência do aparecer do aparecente enquanto tal [des Erscheinens des Erscheinenden als solchen], e esta ciência realiza, ao mesmo tempo, aquilo que toda a filosofia transcendental ambicionava desde Descartes e Kant, a saber, uma fundamentação última do conhecimento, liberta de todos os pressupostos não provados na medida em que os elucida. Esta fundamentação do conhecimento distingue-se, com certeza, por razões de fundo, daquela que o idealismo crítico clássico e os pensadores subsequentes tinham em vista. Ela não é, nomeadamente, uma fundamentação argumentativa, re-apreendendo tudo a partir do eu, enquanto conceito elucidativo último, mas sim uma fundamentação indicadora, amostrante [aufweisende], demostrante [ausweisende] da própria ideia de uma fundamentação. ${ }^{2} \mathrm{O}$ eu não aparece, aqui, nem como fundamento da objectividade, nem como único princípio produtor do mundo aparecente, mas, desde o início, fala-se de uma correlação do aparecente e do aparecer, a qual, apreendida como legalidade

1 (C Jan Patočka Archive, Prague. Todos os direitos em língua portuguesa para Centro de Filosofia da Universidade de Lisboa e Pedro M. S. Alves.

2 Na fenomenologia, é rica a semântica de weisen e de seus derivados - beweisen, aufiveisen, ausweisen, hinweisen, abweisen, zurïckweisen, etc. No caso presente, trata-se de um jogo de palavras entre aufiveisen (aqui, no sentido de "apontar" e "mostrar") e ausweisen (que, no idiolecto da fenomenologia, nomeadamente a husserliana, contém a dupla ideia de mostrar e de legitimar). Ausweisen deve ser aqui entendido justamente como uma conjunção das duas ideias (mostrar e legitimar), a saber, como uma legitimação que se efectiva como um mostrar ou um trazer à luz na evidência correspondente. Para manter este sentido, optámos por recuperar o arcaísmo "demostrar", o qual, sendo a mesma palavra que "demonstrar" (que se reserva para beweisen, também, por vezes, traduzido por "prova"), tem a vantagem de não estar semanticamente associado à ideia de processo lógico-dedutivo, mas sugerir antes uma justificação imediatamente ligada à ideia de um tornar patente ou visível, o qual, nessa medida, se torna, ao mesmo tempo, uma base de comprovação ou legitimação [N. do T.]. 
de essência e intuída na evidência, é a base demostradora última do ser nos seus modos de doação. Neste sentido, pôde com razão perguntar-se se a fenomenologia representa uma filosofia transcendental no sentido tradicional. ${ }^{3}$ A fenomenologia transcendental deixa muito para trás de si a ideia, costumeira na filosofia transcendental tradicional, de uma fundamentação subjectiva, e sugere, desse modo, a ideia de uma filosofia transcendental assubjectiva, não comprometida com o sujeito separado do mundo. As Logische Untersuchungen, de Husserl, põem-se no caminho da edificação de uma análise de fundo da objectividade no como dos seus modos de aparição; faltou nelas, porém, o esboço de uma questionação radicalmente filosófica, universalmente fundamentadora. Nos tempos posteriores, surgiu uma tal questionação, formulada nas Ideen I, mas com uma notável repetição de um idealismo transcendental sem o seu núcleo de um eu geral e idêntico, essencial para a construção da unidade objectiva. Certamente, há também aqui, em Husserl, o pensamento de fundo de uma correlação omni-abrangente entre aparecer e aparecente, esse pensamento foi até reforçado e elevado ao nível metódico de todo o programa filosófico. No entanto, uma notável combinação de caminhos de pensamento cartesianos e kantianos, a par com o pensamento original de uma fundamentação do conhecimento intuitiva, transcendendo a argumentação, conduziu, nas Ideen, a uma "redução fenomenológica" à pura imanência da consciência, pela qual os objectos devieram fenómenos objectuais cujas legalidades dos modos de aparição foram estudadas pela reflexão, na absoluta evidência da autodoação. A reflexão noética dá o "ser absoluto" do curso de vivências, enquanto o objecto serve como fio-condutor para a análise dos modos de doação. E mesmo depois de a autocrítica da fenomenologia contestar à doação subjectiva o direito a uma evidência adequada, a procura de um núcleo de doação absoluta permanece como fio-condutor da problemática filosófica da fundamentação. Evidência e reflexão são implicações da verificação ${ }^{4}$ - assim reza uma fórmula pregnante da interpretação do husserlianismo a partir do pensamento kantiano-transcendental a respeito da fundamentação; e mesmo quando a autodoação absoluta deva ser cunhada como uma ideia em sentido kantiano e a redução não chegue ao seu fim, o retorno reflexivo do sujeito a si próprio é o campo de fundamentação em que sempre se pensa.

${ }^{3}$ Ludwig Landegrebe -"La phénoménologie est-elle une philosophie transcendentale?", in Études Philosophiques, $9^{\mathrm{c}}$ année 1954, n. ${ }^{\circ}$ 3, pp. 315-323.

${ }^{4}$ Cf. G. Funke, na sua conferência, muito bem organizada do ponto de vista sistemático, dada no congresso de fenomenólogos no Schwäbisch Hall (Baden-Württemberg), entre 8 e 11 de Setembro de 1969. 


\section{I}

Uma reflexão crítica sobre o empreendimento de uma filosofia transcendental fenomenológica tem de partir de uma análise do pensamento dos modos de aparição do ente. $O$ estudo dos modos de aparição foi substantivamente renovado por Husserl, prosseguido por Scheller numa série de críticas a Husserl, sublinhado por Heidegger como o essencial da fenomenologia e, recentemente, outra vez energicamente rememorado por Tugendhat. Esta reflexão deve bem desenvolver as suas teses por meio de contextualizações históricas, tal como nós o tentaremos fazer de seguida, de uma forma indicativa.

Seja aqui apresentada a sétima carta de Platão, cujo passo relevante se $^{5}$ interpreta, em minha opinião, de um modo completamente inadequado quando é restituído apenas como uma doutrina acerca dos graus de conhecimento. ${ }^{6} \hat{E}$ dito que, para cada coisa - seja ela uma figura geométrica, como a recta e o círculo, uma obra natural ou artificial, ou a sua qualidade, etc. -, há uma triplicidade que sempre deve ser percorrida se se quiser obter um olhar firme (episteme) sobre a coisa na sua autodoação presente; por assim dizer, três "entidades" objectivas, "exteriores" à alma, e, depois, em quarto lugar, ainda outras coisas que pertencem apenas à alma e que nela se desenrolam. O importante, neste caso, são não apenas os "graus", mas também a circunstância de o ente dado para apreensão não se poder mostrar de nenhuma outra maneira a não ser através e na base de certos modos de aparição, modos de aparição que, não sendo certamente a própria coisa, pertencem essencialmente a este mostrar enquanto tal.

Conspícuo em grau extremo é, agora, a maneira como esses modos de aparição são descritos. Eles são quase os mesmos que, mais de dois mil anos depois, retornam nas Logische Untersuchungen: o nome (a simples significação, espiritualmente mostradora na direcção da própria coisa); o logos, o enunciado, ou melhor, o sentido do enunciado, desta maneira harmonicamente concordante; a imagem, o que é por vez primeira intuitivamente preenchente, o exemplo, a primeira corporização. O que é indicado e simplesmente intentado converte-se aqui, paulatinamente, no preenchimento, e quando nenhuma ilustração que venha simplesmente de nós, mas sim da coisa, quer dizer, do seu presente vivo, tem lugar, chega também este inteiro

${ }^{5}$ Platão - Cartas, pp. 342b e ss.

6 A passagem comentada por Patočka, que se encontra na Carta VII, é a seguinte: «Para cada um dos entes, há três coisas, por meio das quais se gera necessariamente o saber [episteme]; e este é o quarto; e como quinto temos de pôr o próprio ente, que é cognoscível e verdadeiro. Essas coisas são: primeiro o nome [onoma], segundo a definição [logos], terceiro a imagem [eidolon]» (Platão, Carta VII, 342b, tradução do grego de Maria José Figueiredo) [N. do T.] 
movimento ao seu ponto de repouso, já que ele chegou à meta: a própria coisa está aí, é alcançada.

A estas coisas, que aí se chamam: a) simples significação, b) sentido do juízo, c) intuitivo e presente "corporalmente" [leiblich], correspondem agora processos, "que temos de estabelecer que constituem um todo uno, que não está nos sons nem nos formatos dos corpos, mas nas almas", ${ }^{7}$ os quais se poderiam interpretar como sendo: a) a intenção simples, monorradial, b) a intenção do sentido judicativo na polirradialidade, c) o preenchimento da intenção e intuição "corporal" [leibliche], a qual também se pode designar como o olhar firme da própria coisa (episteme). ${ }^{8}$

Esta doutrina acerca dos modos de aparição não foi levada, em Platão, a um real desenvolvimento, pois ela própria foi desde logo interpretada de um modo objectivístico-metafísico: onoma, logos e eidolon, enquanto algo "sensível", são vistos como a opinião, a alethes doxa e a episteme são vistas como algo anímico, "a própria coisa", como ser ideal. Deste modo, não chega a ter valia este início extraordinariamente importante da doutrina dos modos de aparição; cada modo de ser é interpretado, em consequência, como algo dado num olhar uniforme, coisa que, compreensivelmente, deveria conduzir a um nivelamento das diferenças realmente vistas. Não o mesmo em diferentes modos de aparição, mas antes coisas diferentes no mesmo modo do olhar presente - isto tornou-se o fio-condutor da interpretação. $O$ teor de entidade venceu aquilo que possibilita o acesso ao ente.

O problema da aparição do ente foi formulado tentativamente por Aristóteles, em Peri psyches, $431 \mathrm{~b} 20$ e sgs. $^{9}$ Para que as coisas apareçam, quer

7 Platão-Carta VII, 324c (tradução de Maria José Figueiredo) [N. do T.]

${ }^{8}$ Nesta aproximação da lição da Carta VII e de alguns núcleos conceptuais da fenomenologia, Patočka faz intevir as distinções husserlianas, expostas nas Investigações Lógicas, entre acto nominal, ou monorradial, e acto proposicional, ou polirradial, bem como a dualidade da intenção signitiva e da intuição doadora, pela coincidência das quais se efectiva o preenchimento (coincidência entre objecto visado e dado), cujo correlato objectivo é a verdade. Para a distinção entre actos mono e polirradiais, ver, por exemplo, Investigações Lógicas, Quinta Investigação, $\S 38$, Hua XIX/1, especialmente pp. 501 e ss.; para a vivência do preenchimento, ver Sexta Investigação, Hua XIX/2, passim [N. do T.].

${ }^{9}$ Porque a passagem de Aristóteles é pormenorizadamente comentada por Patočka, inserimo-la aqui para comodidade do leitor: «Agora, resumindo aquilo que foi dito acerca da alma, afirmemos de novo que a alma é, de certa maneira, todos os seres. De facto, os seres ou são sensíveis ou inteligíveis; e, de certa maneira, o conhecimento é o que é cognoscível, e a sensação o que é sensível. Mas temos de investigar de que maneira é isto assim. O conhecimento e a sensação estão divididos pelas coisas, o que é em potência pelo que é em potência, o que é em acto pelo que é em acto; e as faculdades sensitiva e cognitiva da alma são estas coisas em potência, a saber, o cognoscível e o sensível; é necessário, pois, que sejam ou estas coisas ou as suas formas. Mas não são estas coisas; de facto, não é a pedra que está na alma, mas a forma da pedra. A alma é como uma mão; com efeito, a mão é um instrumento de instrumentos, e o intelecto é uma forma de formas, assim como a sensação é uma forma dos sensiveis. Ora, como parece que nenhuma coisa é separada a não ser a extensão sensivel, as coisas inteleccionáveis - quer as chamadas abstracções, quer to- 
dizer, para que a sua forma surja e se mostre, é necessário um ente de natureza particular, a saber, a psique, o princípio vital [Lebendigkeit]. Apenas quando há o princípio vital pode o ente mostrar-se. O princípio vital é, porém, a disposição activa para a obra de um corpo orgânico [Leib] não produzido, o qual está dotado de todas as coisas com as quais pode ser mantido em função. Uma das funções (operações) mais efectivas que distingue os seres animados é, contudo, precisamente, o deixar-aparecer [Erscheinenlassen]. Há, porém, um deixar-aparecer, por um lado, daquelas coisas que são mutáveis, pois estão num aqui e num agora, e, portanto, apenas se podem encontrar num aqui-agora (aisthesis), e, por outro lado, daquelas outras acerca das quais o agora não tem qualquer sentido, que são, neste sentido, supratemporais (noesis). Sob o ponto de vista do aparecer, tudo o que é (ta pragmata) se vê repartido em aistheta e noeta, e certamente tanto segundo a sua possibilidade quanto segundo a sua realidade.

Por que razão é a alma inevitavelmente necessária para a aparição das coisas? Porque as formas das coisas, porquanto não aparecem, estão em alguma parte, isto é, nas coisas - não há mesmo nenhumas formas para ta megethe -, e quando elas surgem como formas puramente para si, necessitam de um lugar. Este lugar deve ter ele próprio uma forma, um viso ${ }^{10}[$ Aussehen] de um tipo singular - deve ser algo que possa receber outras formas, deve ser eidos eidon, para que possa devir lugar dos eide. Dito em palavras modernas: deve ter um lado "noemático", deve poder contrapor-se ele próprio "objectivamente" no interior da alma. Isto expressa-o Aristóteles por meio de uma analogia singular, segundo a qual a alma é qualquer coisa como uma mão, que é instrumento dos instrumentos, isto é, que dá à partida o carácter instrumental a tudo o que pode servir como instrumento - sem mão, não haveria qualquer instrumento, cada instrumento devém um utensílio primeiramente pela mão, e assim a alma faz também de todas as formas propriamente formas, isto é, coisas aparecentes; mas, com isto, a mão não altera de modo algum aquilo que manipula, isso permanece aquilo que era $\mathrm{e}$

das as disposições e afecções dos sensíveis - estão nas formas sensíveis. Por via disto, ninguém pode aprender nem compreender nada sem o sensoriar; quando contempla, é necessário que contemple simultaneamente uma imagem mental; de facto, as imagens mentais são como as sensações, só que sem a matéria. Mas a imaginação é diferente da afirmação e da negação; pois a verdade ou falsidade são combinações de intelecções. E em que é que as primeiras intelecções diferem das imagens mentais? Nem elas nem as outras são imagens mentais, mas não podem ocorrer sem as imagens mentais» (tradução do grego de Maria José Figueiredo) [N. do T.].

${ }^{10}$ Aussehen significa aqui um "parecer", um "aspecto" ou "semblante". Para manter a referência directa ao ver, que Patočka explora no seu texto em conexão com o grego eidos, preferimos a expressão "viso", algo inusitada mas pertencente ao léxico do português, a qual, significando "aparência" ou "rosto", tem a vantagem de transmitir imediatamente a ideia daquilo que de uma coisa está disponível para a visão, é nela visível, mesmo que nenhum olhar actual sobre ela incida [N. do T.]. 
devém, graças à manipulação, aquilo que é, aquilo que continha de disposição, de possibilidade.

Deste modo, pode ser dito que as coisas aparecem na alma sem por isso perderem a sua forma própria, a sua essência. Isto é válido tanto para os aistheta como para os noeta. Assim, tanto aquilo que é singular, encontrado numa situação, como o geral-supratemporal aparecem na alma.

Contudo, é isto suficiente para podermos dizer: a alma é de alguma maneira (ainda por investigar) as coisas? Quer dizer, no seu deixar-aparecer, a alma não é diferente das coisas. Na sua manipulação do instrumento, a mão permanece deste distinta, ela não se identifica de modo nenhum com martelo e agulha, de cuja presença independente ela, pelo contrário, precisa. Aqui reside, por conseguinte, uma distinção: a mão é certamente uma boa analogia para o lugar, mas não para a identidade, melhor, para a identificação; e, no entanto, dela fala Aristóteles porquanto diz: he psyche ta onta pos estin.

A identificação, que tem lugar no interior da alma, não pode ser compreendida se não estiver na alma o poder de ter o mesmo de modos diferentes e, neste quadro, de efectuar uma identificação.

Com a sua tese de que a alma é, de algum modo misterioso, o ente, Aristóteles apreende conjuntamente não apenas a essência da chamada "intencionalidade", mas também a doutrina acerca dos diversos modos de aparição do mesmo.

Apenas que estes diversos modos de aparição do mesmo são imediatamente limitados em Aristóteles a um tipo que, tal como em Platão, determina uma sobrecarga do ente que aparece relativamente ao modo como aparece. $\mathrm{O}$ mesmo, que aí aparece, é interrogado por via da relação do estético ao noéti$c o$, da relação entre o que é para encontrar [des zu Begegnenden] e o que sempre já é [Immer-schon-Seiendes]. Mostra-se que a alma, para se poder ressentir daquilo a respeito do qual o tempo é irrelevante, deve ter tido uma aisthesis e ter-se dela servido numa modificação da phantasia. Assim, a doutrina acerca dos diversos modos de aparição torna-se outra vez uma doutrina dos graus de conhecimento que a alma deve percorrer para se elevar da "superfície sensivel" até à altura da essência do ente.

As especulações da escolástica, particularmente da tardia, sobre o esse intentionale na sua identidade e diferença com o esse reale são desde logo interessantes neste contexto, já que, aí, se reflecte expressamente sobre a objectividade dos conteúdos anímicos enquanto tais. Uma das consequências destas especulações deveria ser, porém, a doutrina acerca do carácter ao mesmo tempo intencional e representativo da "ideia" (isto é, da "representação") na alma, tal como ela se nos depara em Descartes e nos seus sucessores.

Olhando retrospectivamente, poderíamos distinguir uma série de problemas particulares no quadro da problemática da alma enquanto lugar do aparecer. Há desde logo o problema da própria estrutura anímica, enquanto 
ela é o referir-se de qualquer coisa a qualquer coisa, enquanto amostrante de um lado objectivo, "noemático", para falar como Husserl. De seguida, há o que se poderia denominar como o problema de uma identificação transcendente - faz parte dele o problema da natureza representativa ou não-representativa do ser intencional perante o ser real. O terceiro problema seria, depois, o da identificação imanente, o qual se desagrega em dois: primeiro, a composição interna dos momentos do próprio representante e as suas transformaçõés possíveis - é este aspecto que concitará a maior atenção nos tempos sequentes, já que se procurou na análise das ideias o fundamento de cada verdade proposicional; segundo, nunca, porém, claramente destacado, por parte da tradição, de outras correlações, a análise dos diferentes modos de doação, nomeadamente, das possibilidades, implicadas nesses modos, de passar de um para outro, portanto, a interna regulação do aparecente enquanto tal. Como foi já sublinhado (e como deve ser sempre de novo sublinhado), na tradição metafísica, todas estas correlações não apenas não foram claramente distinguidas, como os problemas estruturais da alma e dos modos de doação foram, em benefício da identificação transcendente e da análise do representante, largamente silenciados, desprezados, frequentemente confundidos com estes últimos problemas.

Relativamente a Descartes e à época cartesiana, necessitaríamos urgentemente de um trabalho de fundo sobre o estado deste problema. Na falta de um tal trabalho, indiquemos o seguinte. Descartes aceita a identificação transcendente; porquanto não se trate da existência da res cogitans, garantida na certeza de si do espírito, a identificação transcendente acontece por meio dos representantes do ente formal, objectivamente (intentionaliter) presentes no espírito humano, que aí se chamam "ideias". Em conexão com isso, as ideias (não, portanto, os juízos, a apofanse) são primariamente denominadas "verdadeiras", se, de facto, estão em condições de desempenhar a função representativa. Tais ideias têm a característica da clareza e da distinção: elas estão internamente articuladas e não se confundem com as outras. O teor das ideias é formulado em razões, isto é, em sentidos judicativos, que podem formar cadeias de evidências. Ou com base no seu teor de evidência ou por outras causas, estes sentidos judicativos são afirmados ou negados pela faculdade de julgar, que depende do livre arbítrio: Os caracteres dóxicos, "objectivos", "noemáticos", talvez ainda outros modos de aparição (presente - ausente, claro - obscuro) são, por conseguinte, implicitamente distinguidos do próprio acto judicativo, se bem que o alcance desta distinção permaneça pouco claro. A sempre possível passagem do evidente para o não-evidente é também objecto de reflexões de fundo; trata-se aí, sobretudo, de enfraquecer o cepticismo, que poderia agrarrar-se a esta mudança, coisa em que, como é bem sabido, Descartes acha mesmo neçessário o trabalho da prova ontológica. 
No fundo, também Descartes permaneceu fiel à tradição metafísica, porquanto atribui clareza e distinção à ideia, como seus caracteres internos, tomando, desta maneira, como já regulado o problema dos modos de aparição do ente e, em ligação com isso, considerando o subjectivo com o simples acto de ver ou não ver, de assentir ou dissentir.

Leibniz e a tradição leibniziana são importantes para o posterior desenvolvimento do problema. O tratado Meditationes de cognitione, veritate et ideis é o ponto de partida da discussão moderna do problema dos modos de aparição, o qual aparece aqui, naturalmente, cartesianamente travestido enquanto problema das ideias.

Todas as quatro dimensões da problemática são explicitáveis em Leibniz, se bem que não estejam expressamente sublinhadas. Ele parece estar muito pouco interessado no lado subjectivo-imanente, anímico-estrutural, do problema; por isso, utiliza as mais das vezes a palavra "conhecimento" não no sentido de processo de conhecimento, mas sim no sentido do resultado objectivo, da (possível) verdade.

A verdade, se bem que repouse em fundamentos transcendentes, numa concordância com as coisas, está presente apenas nos pensamentos e necessita, por isso, de um representante das coisas no espírito. Este representante são as ideias. Nas ideias está contida a essência (essentia) das coisas. É, portanto, necessário, para que se possa alcançar o conhecimento, isto é, a verdade daquilo que é, conhecer a constituição das ideias e a ordem da sua conexão. Com isso, a identificação transcendente é reconduzida à análise imanente e (posteriormente) à síntese dos momentos do representante, ao tipo e ao modo da sua conexão. Leibniz toma, em princípio, esta conexão como elucidável numa análise que percorre as puras identidades. Neste percorrer das identidades, nesta identificação formal, consiste a essência própria da operatividade cognoscente.

Levanta-se, porém, uma questão que torna necessário considerar a dimensão dos modos de aparição, nomeadamente, a questão de saber como, perante o facto da falta inicial de uma tal análise, nós sabemos que temos ideias. Na verdade, acreditamos muitas vezes encontrar em nós uma ideia quando temos à nossa disposição apenas uma palavra para designar um complexo de representações absurdo, contraditório. Porquanto falemos com entendimento acerca de uma coisa (isto é, entendemos com isso que, a respeito daquilo que se trata, daquilo que visamos, temos uma intenção significativa determinada, a qual também podemos reproduzir no nosso auditor), acreditamos, nomeadamente, que também devemos ter a ideia. Mas uma tal intenção significativa pode ser frustrada - Leibniz fala de um conhecimento cego; porquanto reconduzamos este conhecimento "cego" à sua "origem" intuitiva, constataremos que ele nada tem aí que lhe corresponda.

Está aqui implicitamente contido que posso ter o mesmo objecto de dois modos: uma vez, numa intenção não preenchida, outra vez, na sua própria 
presença. Esta conexão implícita não é desenvolvida mais além, a essência da identidade que aí se realiza não é discutida, mas, em vez disso, são apresentadas as seguintes considerações:

1. Pode-se designar uma intenção não preenchida como uma "representação obscura". Não está nela contido aquilo que possibilita o reconhecimento do objecto, que se nos depara na sua presença viva, e a sua distinção de todos os outros - com isto, Leibniz não quer dizer que não haja nenhuma relação entre esta representação obscura e a representação clara, a qual contém as marcas distintivas da própria coisa. A representação clara surge quando somos levados diante da própria coisa; Leibniz pensa, aqui, na doação sensivelmente presente. A própria coisa presente dá, portanto, uma representação clara; Leibniz não a distingue de uma ilustração imaginativa [Veranschaulichung], a qual, manifestamente, poderia também ser considerada como um tipo de representação clara. A representação clara é, por conseguinte, uma representação que preenche a intenção significativa.

2. Ora o preenchimento da significação não é ainda um conhecimento em sentido próprio. O preenchimento da significação é um pseudoconhecimento ou um conhecimento de grau inferior. Impõe-se aqui de novo a doutrina metafísica dos diferentes graus do ser e do conhecer. O preenchimento da significação pode ser, ainda e sempre, fictício; ele pode intercalar entre nós e as coisas um representante certamente intuitivo, mas opaco, que não permita ver como se relaciona com aquilo que representa - a estrutura do representado perde-se nele. Podemos falar de um conhecimento distinto apenas aí onde os componentes desta própria estrutura estão presentes, o conhecimento será adequado apenas quando a distinção se estende também aos componentes últimos; e podemos falar de conhecimento intuitivo assim que este conhecimento distinto não seja apenas esboçado simbolicamente, mas realmente consumado - por conseguinte, volta aqui de novo a diferença entre não-preenchimento e preenchimento. Para nós, homens, quase não há conhecimento adequado e intuitivo; podemos-nos aproximar dele apenas na esfera dos números.

A doutrina dos modos de doação aparece em dois lugares: obscuro claro, não-adequadamente intuitivo (simbólico) - adequadamente intuitivo. A oposição de fundo é a oposição cartesiana entre o conhecimento sensível confuso e o saber racional distinto. O claro não exclui o confuso, a clareza sensível é uma multiplicidade confusa, em contraposição a ela está a multiplicidade intelectual que progride até às unidades últimas. Só há o simples na esfera intelectual, no sensível não há, no fundo, nada simples. Torna-se em oposição cognitiva dominante a oposição entre o intelectualmente simples e o sensivelmente múltiplo. Retorna aqui de novo o travestimento platónico do aparecer naquilo que aparece.

$\mathrm{Na}$ escola leibniziana, Bolzano é importante. Ele realça, mais nitidamente que Leibniz o tinha feito, o aspecto objectivo da representação, en- 
quanto "representação em si", em contraposição ao representar subjectivo. Por via da sua compreensão do julgar enquanto tese, Bolzano torna-se, inopinadamente, pai da doutrina das diferentes relações intencionais possíveis ao objecto. À tese contrapõe-se a proposição em si, enquanto seu correlato objectivo. Nestas distinções entre representar, representação e objecto da representação, entre representação com e sem objecto, entre julgar e proposição em si, desenvolve-se progressivamente uma doutrina acerca do objecto e do conteúdo da representação, os quais, pelo seu lado, se distinguem do representar enquanto processo anímico real. Estas distinções bolzanianas constituem, segundo nos parece, um pressuposto indispensável tanto para a doutrina de Brentano acerca da inexistência intencional do objecto, como para a doutrina de Husserl acerca dos diferentes caracteres da objectividade aparecente.

Passamos aqui por cima do problema da aparição e do aparecer na filosofia crítica e no idealismo alemão, por mais tentador que seja tratá-lo. A tradição do idealismo alemão não foi assim tão fundamentalmente relevante para a doutrina husserliana do objecto nos seus modos de aparição como aquela, atrás esboçada, que vem de Platão e Leibniz através de Bolzano e Brentano. Em oposição aos pensadores anteriores, Brentano desenvolveu principalmente o aspecto da estrutura anímico-subjectiva. Tal aconteceu em correlação com a aspiração a um devir-positiva da filosofia, enquanto ciência, sobre o fundamento de uma psicologia científica. Enquanto ciência, a psicologia precisa de uma delimitação do seu domínio próprio de fenómenos. Esta consolidação faz-se através de uma separação dos fenómenos "psíquicos" e "físicos". Tal acontece de acordo com duas notas distintivas: uma remonta a Descartes, a outra, a Aristóteles e à tradição escolástica. O motivo cartesiano reza assim: o fenómeno psíquico assegura a existência do que aí aparece, o que aí aparece existe, portanto, na certeza, coisa que não pode ser dita dos fenómenos físicos, os quais mostram, num primeiro momento, apenas uma "inexistência imanente" no psíquico. O retorno a Descartes volve-se, porém, numa ultrapassagem do mesmo Descartes, porquanto a multiplicidade da relação intencional à objectividade se torna expressamente tema de investigação. Brentano empenha-se numa verdadeira análise desta relação imanente, para a qual desempenha serviços importantes a compreensão, já surgida em Bolzano, do juízo como tese.

Com isto, está também operante, em Brentano, o tema dos modos de aparecer, sob a forma de uma distinção entre julgar cego e evidência judicativa. Este tema é fundamental para o conjunto da sua doutrina do conhecimento, se bem que ele não logre libertá-lo da sua fixação na metafísica tradicional; o evidente é decidido por meio de teses metafísicas e não comprovado num regresso até aos próprios modos originários de aparição. Assim, por exemplo, a doutrina tardia de Brentano de que não há senão coisas depende, como resultado evidente, de teses ontológicas. 
A problemática do intencional conduziu a uma alternativa debatida entre Brentano e a sua escola: multiplicidade dos modos de referência da consciência à objectividade unitária ou multiplicidade das objectividades com idêntica referência da consciência ? $^{11}$ A filosofia tardia de Brentano está determinada pela sua decisão pela multiplicidade dos modos de referência da consciência, a qual, pelo seu lado, está condicionada por uma metafísica substancialista, e também mesmo por uma metafísica da alma.

\section{II}

A importância das Logische Untersuchungen, na sua segunda parte, reside no facto de o problema do modo de doação do objecto de pensamento, ou melhor, das objectualidades de pensamento, ter sido desenvolvido em toda a sua amplitude, se bem que no âmbito das estruturas lógicas, âmbito certamente limitado, mas contudo central para a problemática coeva da fundamentação da ciência. Ao "ou... ou" da escola brentaniana foi aqui contraposto um "não só..., mas também". Os caracteres téticos e os modos de doação foram descobertos e estudados enquanto estruturas gerais do pensamento e da experiência. No entanto, permanecem aí problemas por resolver.

A mais importante hipoteca com que a determinação brentaniana dos fenómenos psíquicos enquanto actos intencionais onerava o subsequente desenvolvimento da nossa questão era a sua determinação dos actos psíquicos como qualquer coisa para si própria internamente dada. Esta determinação contribuiu essencialmente, em nossa opinião, para a apreensão do subjectivo como objecto. interno, o qual, mesmo quando, diferentemente de Brentano, não estava sempre sobre si próprio lateralmente dirigido, era compreendido como principialmente captável pelo menos num acto subsequente de reflexão. Esta versão brentaniana do cartesianismo envolveu decisões ontológicas prévias que, inobservadas, actuariam mais além.

Certamente que Husserl encarou como errónea a doutrina brentaniana da repartição dos fenómenos em físicos e psíquicos, e crtiticou também, com razões concludentes, a doutrina de Brentano acerca do psíquico como algo internamente percepcionado, mesmo que esta percepção se faça em modus obliquus. Husserl viu nisso uma regressão ao infinito. No entanto, nas teses pelas quais corrigiu a doutrina do objecto imanente, permanece um resíduo não dominado da concepção brentaniana. Se o objecto intencional não é imanente, mas antes transcendente ao sujeito, então segue-se daí necessariamente, por via da conservação da concepção brentaniana do psíquico como objecto interno, a distinção fundamental entre vivência e fenómeno. A vivência não aparece, mas está antes simplesmente aí como qualquer coisa

"Alternativa elaborada por Ernst Tugendhat - Der Wahrheitsbegriff bei Husserl und Heidegger. Berlin: Walter de Gryuter, 1967, pp. 28-32. 
"real" [reelles], ${ }^{12}$ transcorrendo temporalmente; ela deixa, porém, aparecer. Com base na vivência, aparecem transcendências. As vivências podem, então, elas próprias tornar-se subsequentemente objectos da reflexão, e, no seu modo originário, a reflexão é uma captação interna em original, a vivência está para si "corporalmente" [leibhaft] presente e, mesmo que não adequadamente, é pelo menos captada na apodicticidade.

Só podemos compreender a doutrina das Logische Untersuchungen no seu todo com base, por um lado, na importante descoberta de que não são de modo algum os "fenómenos psíquicos" que originariamente nos aparecem, mas antes as próprias coisas, objectividades e transcendências de tipo físico-reico ou lógico-ideal, e, por outro lado, com base na manutenção do dogma brentaniano do acesso originário ao psíquico num tipo de viragem que sobre ele se dirige como objecto. Como já indicámos acima, este acesso é pensado por Husserl de um modo diferente de Brentano, o qual se agarrou à tese da consciencialidade [Bewußtheit] originária do psíquico e a pretendeu justificar através do modus obliquus da direccionalidade da consciência. Husserl não duvida, porém, da existência de actos, enquanto vivências, que são eles próprios originariamente acessíveis para a reflexão; ele faz mesmo deles o fundamento da aparição, de cuja compreensão tudo o mais depende, e aos quais deve ser reconduzido todo o esclarecimento do mundo e do ente mundano. Pretendemos mesmo arriscar a tese de que foi o prosseguimento sistemático desta tarefa que conduziu Husserl ao solo da questionação transcendental na forma que lhe foi peculiar, e que o cartesianismo, que frequentemente se caracterizou como a fatalidade que conduziu Husserl à doutrina do ser absoluto da consciência pura, não é outra coisa senão um elemento não dominado de brentanismo.

Nesta perspectiva, nada mais característico que o tipo e o modo como Husserl procura desarmar as dúvidas de Natorp $^{13}$ a respeito da doação de

12 Husserl distingue entre real e reell e, correlativamente, entre ideal e ideell. Os pares de opostos conceptuais são, de um lado, ideal - real e, do outro, ideell - reell. Ideal diz-se de certas objectividades, como, por exemplo, as significações, os objectos gerais, as objectividades lógicas e matemáticas, que não têm uma individualização no espaço e no tempo; real são as objectividades acerca das quais tal individualização é válida. A outra oposição caracteriza o modo de pertença à consciência dos ingredientes da intencionalidade: enquanto o acto e seus constituintes (sentido de apreensão, modalidades de crença) são elementos do fluxo de consciência, a objectividade enquanto visada através dos actos, se bem que imanente (intencionalmente) à consciência, não é uma vivência ou um seu elemento. Deste modo, os actos são da ordem do reell, os objectos enquanto visados, da ordem do ideell. Porque não há em português forma directa de distinguir entre o alemão real e reell, optámos por traduzir reell por "real" e, para real, porque significa, na nomenclatura husserliana, aquilo que existe ao modo de uma coisa, escolhemos a palavra "reico", directamente formada a partir da palavra latina res e que tem a mesma valência semântica da alemã. [N. do T.].

13 Para o que se segue, ver as exposições muito instrutivas, mas não suficientemente levadas até às suas consequências mais latas, de Iso Kern em Husserl und Kant. Den Haag: Marti- 
algo como um "acto psíquico". Quando Natorp diz: «A existência [do som] para mim é a consciência que tenho dele. Se alguém quer surpreender a sua consciência ainda de outro modo que pela existência de um conteúdo para si, então eu [...] não posso seguir o seu exemplo», Husserl tenta, através de exemplos concretos, pôr-lhe diante a doação do acto, mostrar-lha. Ele procura fazê-lo por meio de uma análise mais profunda do conceito de "existência de um conteúdo para mim". Há diferentes modos do notar: um conteúdo está aí para nós de um modo diferente quando está simplesmente implícito e quando é captado como algo explicitamente destacado. Chama, então, a atenção para a diferença entre sensação e percepção: «diferentes actos podem percepcionar o mesmo e, porém, sentir coisas diferentes» e, por outro lado, diferentes actos podem apreender de modos diferentes as mesmas sensações. A própria apreensão, diz Husserl, não é nenhuma afluência de novas sensações, mas antes um "carácter de acto", um "modo da consciência", "da disposição". Um exemplo da esfera preponderante da percepção visual fala de uma caixa que vejo de diferentes lados e que permanece a mesma nesses diferentes aspectos. Nós vivemos aí a "consciência de identidade", a pretensão de captar a identidade. Isto pensa-o Husserl no sentido seguinte: são certamente dados, de um e do outro lado (para duas rotações diferentes da caixa), diferentes conteúdos de sensação, os quais são, porém, apreendidos no "mesmo sentido", a apreensão (apercepção) segundo este "sentido" é um carácter da vivência que produz, por vez primeira, a "existência do objecto para mim". Uma outra esfera de exemplos elucidativos é fornecida pela comparação da percepção com a recordação e de ambas com a prefiguração [Vorbildlichung] (por exemplo, por meio de pinturas, estátuas, etc.), mas sobretudo pelas expressões linguísticas [Ausdrücke]. Qual a diferença entre o arabesco e a consciência especificamente simbólica, que a ele se liga, mas onde a compreensão do conteúdo significativo que aí se exprime eclipsa o arabesco? Em que consiste, particularmente, a consciência significativa vazia de uma palavra que ouvimos na conversação, sem tornar intuiva a coisa que ela nomeia, mas sabendo, porém, daquilo que se trata? Em resumo: as sensações e os actos "apreensivos" ou "aperceptivos" são vividos, mas não aparecem objectivamente; eles não são vistos, ouvidos, percepcionados por um qualquer "sentido". Por outro lado, os objectos aparecem, são percepcionados, mas não são vividos. ${ }^{14}$

Perguntamos agora: não se diferenciam, então, os diferentes modos da "existência de um conteúdo para mim" precisamente por estar aí, de cada vez, um outro aparecente, em diferentes campos de aparição, e dotado de

nus Nijhoff, 1964, pp. 360 e ss, onde, tal como posteriormente verifiquei, a "intencionalidade noemática" é reconhecida e caracterizada como construtiva.

14 E. Husserl, Logische Untersuchungen. Halle, M. Niemeyer, 1913, $2^{\text {a }}$ edição, tomo II, Primeira Parte, pp. 380-385. 
outros caracteres de aparição? Quando - ao despertar, por exemplo - me encontro por assim dizer submerso em sensações, passivamente entregue a elas, antes que o meu viver receba os contornos das coisas, não me aparece aí outra coisa totalmente diversa das coisas, nomeadamente uma névoa, um caos, que, no entanto, tem ainda um carácter objectual? Não é a ligação peculiar que apresenta o vermelho como lado objectual, como vermelho de um maço de cigarros, uma estrutura objectiva? Onde se poderá observar aí qualquer coisa como um "acto" e uma vivência? Aparecem-me coisas com caracteres objectivos e ainda outros caracteres, téticos, por exemplo; há aí uma diferença entre os caracteres que adscrevo à "própria coisa", como suas características, e outros caracteres, que certamente estão também copresentes, não como pertencentes à coisa, porém, mas com cuja ajuda, por assim dizer, e sobre o fundamento dos quais a coisa aparece; mas os caracteres de ambos os tipos aparecem no mundo, no campo de aparição "diante" de mim, não estão aí presentes, de modo algum, como vivências, como algo subjectivo. $\mathrm{O}$ originário são as coisas e os caracteres cousais, que aparecem situados "diante de mim", juntamente com e sobre o fundamento de outros caracteres não-cousais, mas mesmo assim objectivos. Aquilo sobre cujo fundamento as coisas aparecem está ele próprio presente cousal e não subjectivamente; aquilo que é lançado em campo por Husserl contra Natorp, o "vivido", não é de modo algum dado, e viola o "princípio de todos os princípios" (segundo o qual a instância última, a que se tem de recorrer nas matérias de conhecimento, é o dado, mas apenas na medida em que é efectivamente dado) ${ }^{15}$ ao invocar um pretenso fundamento vivencial na análise do aparecer, fundamento que não está dado neste.

Tomemos o caso da "consciência significativa vazia" - que quer ela dizer? O próprio Husserl admite finalmente que, também neste caso, está aí ou seja, está diante de nós - qualquer coisa mais que a face sonora da palavra, o arabesco, etc. Este "mais" não é, porém, nada de subjectivo: é a coisa que está aí - como também foi dito mais tarde por Husserl - num modo deficiente de doação, como "não estando ela própria â̂", mas, no entanto, como estando de algum modo indicada; por conseguinte, está aí também a indicação da coisa, que não é nenhuma vivência, nada de subjectivo, no sentido do egológico. O mesmo se passa com os caracteres téticos: é a coisa que aparece como duvidosa, no carácter da certeza simples, inquebrada, e depois de novo como problemática, etc.

15 Patočka refere-se aqui ao "princípio de todos os princípios", apresentado por Husserl em Ideen I, \$24, Hua III-1, p. 51, cuja formulação é a seguinte: «[...] cada intuição originariamente doadora é uma fonte de direito do conhecimento, tudo o que se nos oferece originariamente (por assim dizer, na sua realidade viva) na "intuiçäo" é para ser tomado simplesmente tal como se dá, mas também apenas dentro dos limites em que aí se dá [...]»" [N. do T.]. 
Naturalmente, estes caracteres téticos e de doação são o índice de que o aparecente aparece para qualquer um, e, deste modo, nós também não os atribuímos à própria coisa como ingrediente daquilo que aí aparece. $\mathrm{O}$ que contestamos é a permissão para fazer daquilo sobre cujo fundamento algo aparece ainda outra vez um novo objecto de uma "percepção interna" possível, que o apreenda "em original", a permissão de o captar numa suposta "reflexão sobre a vivência pura". O "subjectivo" dos caracteres téticos e dos modos de doação está tão "lá fora" (diante de mim) como as próprias coisas aparecentes. Se ele próprio não aparecesse, Husserl não teria podido considerá-lo, nos seus trabalhos posteriores, como um carácter noemático. ${ }^{16}$ São bem estes caracteres que têm como pretexto e finalidade a coisa enquanto aquilo que é, que têm, por assim dizer, a coisa em vista, a deixam aproximar ou afastar, estar aí clara ou veladamente, apresentar-se; nisto residem as tarefas mais próprias da fenomenologia, a saber, na descrição destes processos, deste brotar das próprias coisas. É, pelo contrário, por razões de fundo incompreensível como pode a vivência começar por ser, em si própria, origem do aparecer do transcendente. Isso não está dado e não pode ser dado. Aqui reside o perigo de que a fenomenologia renuncie a si própria, às suas descobertas no domínio da aparição, dos modos de doação, e se dirija para o terreno da construção subjectiva.

"Diferentes dados são apreendidos no mesmo sentido", "são animados pela mesma intenção" - quer quer isto dizer? Nada mais nem nada menos que isto: os diferentes lados de um objecto de percepção, por exemplo, de uma caixa, aparecem como lados da mesma coisa. A coisa que áparece nestes lados não é, porém, compreensivelmente, nenhuma intenção; ela é uma coisa, o que é firmemente mantido através de diferentes perspectivas, ela é o que é compreendido através de perspectivas e não o próprio compreender. Deve haver, certamente, uma compreensão; ela não é nada diferente deste aparecer da coisa; concluir daí que ela deve ser, ainda mais uma vez, reflexivamente captável em original é um pressuposto arbitrário. $\mathrm{O}$ aparecer, isto é, o olhar, através das perspectivas, para a coisa una nelas se apresentando -

16 Patočka refere-se aqui à noção husserliana de "noema completo", exposta nas Ideen I, $\S \$ 90,91$, Hua III-1, pp. 206 e ss., a qual envolve, para lá do sentido (Simn) e do objecto $X$ visado, pertencentes ao "núcleo noemático", também os modos de ser (realidade, possibilidade, verosimilhança, etc.), que são o correlato objectivo das atitudes dóxicas, e os modos de doação (presente, recordado, imaginado, simbolizado, etc.) Todos esses modos são dimensões do objecto e não ingredientes noéticos da vivência enquanto tal. A complementaridade entre a noese, e os seus ingredientes reais, realmente imanentes ao acto, e o noema, enquanto algo objectivo e imanente ao acto apenas de um modo intencional, é o pensamento de fundo da chamada "doutrina da correlação", a qual toma o objecto tal como é visado ou dado, na integralidade dos seus caracteres de sentido, de ser e de apresentação, como o fio-condutor da análise. Patočka pretende desenvolver aqui uma fenomenologia "noemática" e libertar a unidade noemática da imanência intencional da consciência [N. do T.]. 
isso está dado; uma "intenção animadora dos dados" - isso não é captável, não é mostrável, não está dado.

Poderíamos fazer ainda a seguinte reflexão: este olhar através das perspectivas, este transcender do que é sensivelmente dado é, pois, uma prestação que deve ser realizada por qualquer um, que é originada pelo retorno e por um persistir, nesse retorno, de um idêntico, o qual devém então objecto. Tudo isto é uma prestação que deve ser concebida a partir da tendência para a identidade. É certamente assim, e as prestações subjectivas pressupõem possibilidades, nas quais o sujeito vive, procurando realizá-las. Segue-se então daí, porém, que elas estariam disponíveis em original por meio de um acto objectivante da reflexão? Ou não será tudo isto para decifrar precisamente nos fenómenos? Não são as prestações subjectivas tão aparecentes num campo de aparição como as coisas, as quais elas deixam aparecer? No campo de aparição, as coisas deixam vir à luz o egóico, precisamente como o egóico, pelo seu lado, deixa as coisas aparecerem, mas o egóico não é algo captável em si próprio de um "modo absoluto".

Devemos assentar o seguinte: o campo fenomenal é "subjectivo" de um modo diferente do egóico, o qual aparece, ele próprio, no campo fenomenal. Haveria então que perguntar: não deverá, ainda, ser o egóico dado de um modo que o capte imediatamente na sua originariedade? Não é isso que está contido no cogito cartesiano? Certamente que, no ego cogito, o ego é qualquer coisa imediatamente certa. Esta certeza não é, porém, qualquer certeza acerca de um conteúdo, mas antes uma certeza de ser sem qualquer conteúdo, com excepção destoutro: o ego é aquele a quem o aparecente aparece, o aparecer, o campo fenomenal é o seu aparecer. Nada há aí que seja "objectivamente" captável, mas simplesmente uma realizabilidade dos caracteres de exigência [Realisierbarkeit der Forderungscharaktere], caracteres que, no campo fenomenal, se voltam para o eu e o deixam aparecer como realizador.

Em vez da captação do lado noético e do estudo imanente das vivências enquanto tais, em vez de uma redução à pura imanência, que encerra em si a transcedência noemática, deveria pôr-se o estudo do campo fenomenal enquanto estudo da aparição no seu aparecer, um estudo daquele ser fenomenal que consiste na mostração do ente, no deixar aparecer e, neste aparecer, deixar ser aí o próprio ente sem que este devenha um tema, sem que, neste sentido, ele se deixe ocultar no aparecer das coisas.

Há um campo fenomenal, um ser do fenómeno enquanto tal, o qual não pode ser reconduzido a qualquer ente nele aparecente, um campo que não pode ser esclarecido, por conseguinte, nem de modo objectivo-naturalístico nem de modo subjectivo-egológico. O campo fenomenal não é, no seu fundo, autónomo, ele é impossível enquanto ser absoluto, encerrado sobre si mesmo, a sua inteira essência consiste em manifestar outra coisa, descobri-la e apresentá-la. 
A intenção da redução fenomenológica caminhava propriamente para este campo do aparecer enquanto tal, não para o "subjectivo", no sentido de um viver. O mostrar-se do fenoménico, porquanto se oculta naquilo que deixa aparecer, torna supérfluo o procedimento reflexivo de um "despertar" de algo latente, pois o fenoménico está sempre lá, funcionando apenas de modo diferente no caso de se dirigir a outra coisa ou no caso de se dirigir a si próprio. Se o campo fenomenal não tem um ser autónomo, tem, porém, um ser próprio, que consiste precisamente no mostrar.

O sentido objectivo, com base no qual um objecto é visado, os caracteres téticos, os caracteres de doação - que conduziram, primeiro que tudo, à descoberta do importante reenvio aparencial entre a doação vazia, deficiente, e o preenchimento através da presença, correspondentemente, da presença viva, do "ele próprio ấ" do objecto -, tudo isso não é nada de "subjectivo" no sentido de uma vivência real, que "a mim" pertencesse como meu componente, mas tudo isso se insere antes na esfera fenomenal, na qual vivo e me conheço. Neste sentido, também o visado enquanto visado não é nada de psíquico, e, do mesmo modo, também não o é o inteiro "processo" do preenchimento ou decepção de uma intenção objectiva - tudo isso se joga não em mim, mas diante de mim. A este campo pertencem as descobertas das Logische Untersuchungen, particularmente das investigações V e VI, da segunda parte. Está, no entanto, envolvido na essência da nossa crítica que não possamos aceitar sem uma crítica de fundo a concepção husserliana do viver e do acto e, por isso, também o seu conceito de intencionalidade da consciência. Sejam mencionadas, agora, mais algumas dificuldades da concepção husserliana.

Resulta imediatamente da doutrina husserliana do realmente vivido a sua teoria dos "dados originários de sensação" - ou, como ele também lhes chama, dos "dados hiléticos" - e o seu papel na percepção. Esta doutrina foi desde logo criticada, sem que, no entanto, tenha sido fundamental e consequentemente ultrapassada pela maior parte dos seus críticos. Seja citado, neste contexto, um texto de Roman Ingarden em memória de Husserl, ${ }^{17}$ no qual se mostra que tensões e incompatibilidades o próprio Husserl deve ter sentido. Pois, por um lado, o "dado sensível" é fortemente distinguido do acto de apreensão para, de seguida, ser de novo com ele reunido numa unidade. Depois de, nas Ideen, ter sido introduzida a distinção entre noese e noema, isto é, entre, de um lado, o viver e, do outro, o vivido, o estatuto dos "dados hiléticos" torna-se inteiramente problemático, pois de que lado os devemos procurar? Ingarden sublinha que os dados hiléticos são difíceis de colocar em qualquer uma das três unidades que Husserl distingue (a noética,

17 E. Husserl - Briefe an Roman Ingarden. Den Haag, 1968, pp. 123 e ss. 
a noemática e a correlativa), pois falta também em Husserl uma indicação sobre aquilo em que essas unidades se distinguem umas das outras (esta omissão não é um acaso, porque a unidade noética é, verosimilmente, uma pura projecção da "noemática", da unidade do que é dado no campo fenomenal).

Em nossa opinião, os dados, porquanto são vividos, por exemplo, como "qualidades livres" ou "impressões confusas", são precisamente uma aparição diferente - com uma estrutura objectiva inteiramente diversa - da doação de um objecto real, persistindo no espaço através de perspectivas qualitativas. Que os "dados" sirvam, por via da apreensão objectual, para a passagem a uma coisa totalmente diferente que não surge de modo nenhum neles, não significa que haja aqui uma base subjectiva comum para duas "qualidades de acto" diferentes, as quais seriam, pelo menos, parcialmente responsáveis pela direcção objectiva. A "base subjectiva comum" não é nenhum dado fenomenológico, mas antes um pressuposto proveniente da tradição naturalístico-psicológica: a análise dos dados com base na associação, na apercepção e no juízo pertence ao património venerando dos modos de explicação de diferentes escolas psicológicas do século XIX.

Mas também o conceito de acto, tal como se encontra na doutrina husserliana das "pretensões", dos "actos doadores de sentido", das "intenções", não se pode tomar como qualquer coisa descritivamente demostrável. A este respeito, parece-nos que Natorp tem razão quando opina que a consciência não é outra coisa senão a existência de conteúdos, caracteres, reenvios para mim. A questão é, então, saber que é e como podemos apreender este "eu", para o qual estão aí coisas, caracteres e reenvios dinâmicos. Porquanto se procure o eu e a consistência egológica como um dado, um conteúdo, uma objectividade de tipo peculiar, ao lado das coisas não-egóicas, parece-nos que toda a procura será vã e que dará lugar a construções como aquelas que se nos deparam com a "inexistência intencional" brentaniana e sua herança. Por um lado, um acto não é outra coisa senão o sentido objectivo, diferente do próprio objecto aparecente enquanto tal, "no" qual o objecto está diante de nós; deste ponto de vista descritivo, ele não se diferencia dos caracteres posicionais e de doação. Por outro lado, podemos designar como "acto" aquela requisição de si [Selbstinanspruchnahme] que não aparece objectivamente e que é falsificante na procura de uma "percepção" objectiva, a qual temos o direito de atribuir ao "sujeito psicofísico", enquanto destinatário [Adressat] de tais doações que extravasam a própria objectividade, tal como a pressupomos na sua composição "objectiva". Isto é um conceito de acto totalmente diferente do adoptado por Brentano e Husserl, um conceito que se compreende e se interpreta por si, que não é susceptível de nenhuma mostração directa numa "percepção interna" ou num "acto de reflexão". 
Utilizando um caminho de pensamento de Ernst Tugendhat (Der Wahrheitsbegriff bei Husserl und Heidegger), ${ }^{18}$ poderíamos ainda formular do seguinte modo a crítica acima esboçada à fenomenologia clássica, enquanto filosofia transcendental fundamentada numa autocaptação absoluta da consciência reflexiva.

A fenomenologia clássica tornou-se vítima das suas próprias descobertas e do modo impreciso como as formulou. A grande descoberta dos modos de doação e, acima de tudo, do modo da originariedade trouxe consigo o desvendamento da relacão estrutural, talvez efectivamente universal, entre o visar vazio e o preenchimento. Esta oposição é confundida, em Husserl, com uma outra: a oposição entre doação deficiente e intuição. A intuição quer dizer, porém, tipo de doação de um objecto, enquanto o preenchimento pode ter lugar mesmo quando não pode ser mostrado nenhum objecto, nenhuma coisa persistente ou processo cousal. Este quaternio terminorum conduziu às dificuldades da teoria da intuição categorial e eidética, enquanto autodoação de objectos próprios de natureza categorial ou dos universais de tipo platónico. De um modo algo análogo - assim poderíamos completar Tugendhat -, o mesmo se passou a respeito do cogito. A certeza de si da existência do ego, do sum, foi interpretada como presença, esta presença, como autodoação originária; a autodoação originária requer, porém, um objecto correspondente. Supõe-se, enquanto tal objecto, precisamente o acto de consciência, a noese, originariamente captável na reflexão.

\section{III}

É bem sabido que a certeza do eu foi, para Descartes, certeza do ser e da essência. A dúvida hiperbólica conhece um limite intransponível na certeza do eu enquanto certeza da própria existência. Mesmo para a dúvida mais extrema, a existência do eu é um pressuposto. Esta existência não pode ser uma simples aparição, talvez enganosa, de um outro ser, mas aqui a aparição envolve a própria existência, é essencialmente existência-em-aparição, coisa que, para outros existentes, como, por exemplo, as coisas naturais, não tem de ser forçosamente o caso. Neste sentido, pode-se elevar a certeza do eu a princípio filosófico: ela é um pressuposto mesmo para a aparição daquilo que não é uma existência-em-aparição.

É natural, decerto, interpretar a pertença da existência própria à essência da aparição

1. como tese sobre a necessidade de um aparecer objectivo da essência própria,

18 Ernst Tugenhat - Der Wahrheitsbegriff bei Husserl und Heidegger. Berlin: Walter de Gruyter, $1970^{2}$,pp. 194 e ss. [N. do T.] 
2. como tese sobre o eu como fundamento absoluto e necessário da totalidade da aparição enquanto tal.

Ambas as teses são inviáveis, porém. A primeira é a de Descartes e da tradição cartesiana. $O$ facto do aparecer para a existência é aqui interpretado como certeza acerca da objectividade sempre disponível para as determinações, interiormente também disponíveis, da essência própria. Que isto conduza a um beco sem saída, foi o que tentámos mostrar acima.

A segunda é a tese de Fichte e a da tradição do idealismo transcendental em geral: pretendeu-se aqui construir, a partir do eu puro, a transcendência, aquilo que se the contrapõe, coisa que sempre reconduziu, porém, ao postulado de uma actividade inconsciente que não se pode mostrar enquanto tal.

A questão é, agora, a seguinte: quando se pressupõe a existência, como um sum para si próprio claro, não se regressa com isso, necessariamente, a um cogito que se capta a si próprio em original? Tentaremos responder o seguinte: a ultrapassagem do sum em direcção à coisa aparecente não é mostrável fenomenalmente, não podemos trazê-la "diante de nós". O que está aí fenomenalmente será, ao contrário, o facto importante de que não somos nós, mas antes o ser fenomenal que nos permite interpretar que possibilidades do nosso próprio ser estão aí para nós.

O sum não é nenhuma coisa, no sentido de que ele não pode nunca aparecer independentemente, mas apenas essencialmente em ligação com e no contexto de comportamentos relativos às coisas. Por isso, ele aparece sempre como um eu corporal [als ein Leibich], a cujos impulsos o corpo-vivente $[L e i b]^{19}$ aparecente é capaz de obedecer, isto é, corresponde ao corpo-vivente, enquanto egóico, um apelo fenomenal, ele satisfaz ou tenta satisfazer uma exigência cousal aparecente que se abre diante de si (porquanto aquilo que há a executar se anuncia como um carácter "objectivo", como qualquer coisa não satisfeita). Contextos de acção, ocasiões, utensílios que se me oferecem - tudo isso atrai-me ou repele-me, e esta atracção e repulsão, que se efectuam no campo de aparição, é certamente satisfeita pelo meu corpo-vivente. Ao mesmo tempo, o corpo-vivente forma o centro não-dado de uma perspectiva que, nas suas exigências, para mim (que aí apareço corporal e perceptivamente, de um modo que não é nunca total nem susceptível de distanciamento) se volta e, com isso, por vez primeira me "desperta" e me provoca uma reacção. Isto que está sempre presente, que corresponde ou pode satisfazer as exigências e solicitações das coisas, é o meu corpo-vivente. No entanto, eu não me apareço como corpo-vivente, mas antes no corpo-vivente ou por meio dele. Nomeadamente, eu não me apareço menos

19 Traduzimos Leib por "corpo-vivente", em contraposição a Körper, o simples corpo, evitando a tendência costumeira para verter a palavra alemã por "carne", que não só é a tradução óbvia de Fleisch, não de Leib, como perde ainda, ao pôr unicamente o acento na passividade de um ressentir-se, toda a dimensão, própria do orgânico, de ser um centro não só passivo, mas também activo de exploração do mundo circundante [N. do T.]. 
nas exigências e directivas das coisas aparecentes, as quais são para satisfazer, com todos os seus ingredientes de caracteres de aparição e de doação que caracterizam o mundo prático do quotidiano. As coisas aparecentes "têm qualquer coisa para me dizer", elas dizem aquilo que tenho de fazer. Nelas, a presença, o que é apresentado, está cercado por um halo daquilo que não está presente, mas que é, no entanto, possível e que, como possível, me é antecipadamente convidativo, indiferente ou repulsivo. Assim se vê que as coisas aparecentes são originariamente aquilo que é capaz de ser manipulado, conservado, modificado, utilizado, cuidado; originariamente, elas não são senão proveitos de uma actividade que sabe fazer qualquer coisa com elas e que, deste modo, através deste funcionar activo, a si mesma se refere. Assim, eu apareço-me no campo de aparição como uma conexão não explícita de meios e fins, na qual a coisa aparecente e o corpo-vivente, funcionando como realizador, são momentos de sentido indispensáveis, que se completam mutuamente. A própria conexão finalística não aparece, porém, para si própria como uma doação fáctica, mas apenas na constante dinâmica da prefiguração e da realização, que vão no encalço uma da outra. Pode-se dizer que eu estou certamente presente nesta conexão finalística, no seu funcionar activo, mas não objectivamente dado. $O$ eu é uma actividade estruturada em que alguns momentos aparecem como dados, momentos que, porém, seriam destituídos de sentido e não poderiam existir sem o contexto, que não é dado. Assim é o inteiro modo de funcionamento do eu, ou seja, o modo como ele é fundamentalmente diferente do modo de ser das coisas, estados-de-coisas, processos, relações, que aparecem no horizonte deste funcionar. Esta diferença no modo de ser torna impossível que o eu apareça num acto de percepção, pois isso significaria retirá-lo do contexto projecto-realização e torná-o um aparecente no interior e na base desse contexto. $O$ eu não pode também ser agarrado num acto de reflexão - numa "percepção interna", eventualmente - e ser captado "em pessoa". A reflexão egóica deve ter um carácter totalmente diferente, um carácter essencialmente prático e uma origem na essência originariamente prática do nosso contexto vital.

Se as considerações anteriores são correctas, podemos também juntar-lhes as seguintes consequências.

Não se pode com razão manter o próprio conceito husserliano de fenómeno, da fase transcendental, enquanto correlato do defluxo subjectivo, "no qual o objectual se constitui”. O fenómeno não é nenhuma operação de uma constituição subjectiva, mas, ao contrário, as possibilidades "subjectivas" só no fenómeno se tornam, elas próprias, por vez primeira claras.

Há um plano fenomenal, que é denominado por Heidegger "a compreensão do ser", plano a partir do qual as coisas aparecentes, e também nós próprios, recebem aquelas determinações que são próprias a elas e a nós, enquanto entes. Este plano fenomenal não é de modo nenhum o nosso projecto, ele não é nenhuma obra da nossa subjectividade, mas antes um campo 
que devemos pressupor como fundamento de toda a claridade e acerca do qual não tem qualquer sentido transferi-lo para dentro de nós, para depois o projectar para fora de nós na forma da "liberdade". Também não é nossa obra a compreensão do ser, mas somos antes nós, que somos bem uma existência em aparição, que dependemos da compreensão do ser, e é algo equívoco que Heidegger, numa certa fase do seu filosofar, tenha dito que apenas a liberdade pode deixar que para nós um mundo valha. O mundo - isto é, as possibilidades do nosso ser enquanto ser essencialmente "extático" - não nos é aberto pela liberdade própria, mas é antes a própria liberdade que é aberta pela compreensão do ser, juntamente com outros conteúdos mundanos aparecentes. Não somos nós, ou o nosso ser-aí [Dasein], quem, num projecto de mundo, dá o entendimento de qual seja o ente com que nos podemos relacionar, e como, mas é antes à compreensão do ser, ao fenómeno enquanto tal, que estamos disso devedores - não se pode nem é necessário ir mais além disto. A transcendência do ser-aí não é algo que saia dele próprio e que se projecte para fora; neste sentido, ela não é nenhum "projecto", mas antes um estar-fora-de-si e um receber-se, ambos essenciais. 